\title{
O mosaico vegetacional numa área de floresta contínua da planície litorânea, Parque Estadual da Campina do Encantado, Pariquera-Açu, SP ${ }^{1}$
}

\author{
MARCIO SZTUTMAN² e RICARDO R. RODRIGUES ${ }^{2,3}$
}

(recebido: 30 de outubro de 2000; aceito: 21 de fevereiro de 2002)

\begin{abstract}
Vegetational mosaic of contiguous forest area in a coastal plain, Campina do Encantado State Park, PariqueraAçu, SP). Our objective in this paper was to characterize the floristics, structure and physiognomy of three different forests in distinct physiographic situations of the coastal plain. We sampled a forest over a non deep peat deposit (shallow peat forest), a forest over a deep peat deposit (deep peat forest) and a forest in a firm and dry soil (hillock forest), all these established in the Campina do Encantado State Park, Pariquera-Açu/SP, Brazil. We carried out a phytosociological survey trough blocks of contiguous plots of $10 \times 10 \mathrm{~m}$ - with a total area of $1.04 \mathrm{ha}$ - where all trees with $\mathrm{DBH} \geq 4.8 \mathrm{~cm}$ were sampled. We found a total number of 144 species, where 112 were in the hillock forest, 46 were in the shallow peat forest and five were in the deep peat forest. There was a small similarity within the three forests, with just a few species in common. This was specially remarkable when comparing the two peat forests with the hillock forest. Hillock forest presented a high Shannon diversity index $\left(\mathrm{H}^{\prime}=4.06\right.$ nat.ind. $\left.{ }^{-1}\right)$, that is typical of tropical forest environments. The shallow peat forest presented the expected Shannon's diversity index for this type of environment in coastal plains $\left(\mathrm{H}^{\prime}=2.98\right.$ nat.ind. $\left.^{-1}\right)$. The deep peat forest presented a very low Shannon diversity index $\left(\mathrm{H}^{\prime}=0.82\right.$ nat.ind $\left.^{-1}\right)$ - the lowest ever registered for southern and south-eastern Brazil. The heterogeneity of the vegetation in continuous forested areas - conditioned by coastal plain physiographic features - shows that the protection of the greatest number of environmental situations is needed to promote in situ biodiversity conservation.
\end{abstract}

RESUMO - (O mosaico vegetacional numa área de floresta contínua da planície litorânea, Parque Estadual da Campina do Encantado, Pariquera-Açu, SP). Este trabalho teve como objetivo caracterizar a florística, estrutura e fisionomia de três florestas em distintas situações fisiográficas da planície litorânea. Foram amostradas uma floresta sobre turfeira pouco profunda (floresta turfosa rasa), uma floresta sobre turfeira profunda (floresta turfosa profunda) e uma floresta em solo firme e seco (floresta sobre morrote), todas situadas na área de floresta contínua do Parque Estadual da Campina do Encantado, PariqueraAçu SP. Foi realizado o levantamento fitossociológico através de blocos de parcelas contíguas de $10 \times 10 \mathrm{~m}$ - totalizando 1,04 ha $-\mathrm{e}$ amostradas todas as árvores com DAP $\geq 4,8 \mathrm{~cm}$. Foram encontradas ao todo 144 espécies, sendo 112 na floresta sobre morrote, 46 na floresta turfosa rasa e cinco na floresta turfosa profunda. A similaridade entre as três florestas foi baixa, com poucas espécies em comum, principalmente em relação às florestas turfosas e a floresta sobre morrote. A floresta sobre morrote apresentou alta diversidade, típica de ambientes florestais tropicais $\left(\mathrm{H}^{\prime}=4,06\right.$ nat.ind. $\left.^{-1}\right)$. A floresta turfosa rasa apresentou o valor de diversidade dentro do esperado para formações alagáveis das planícies litorâneas $\left(\mathrm{H}^{\prime}=2,98\right.$ nat.ind..$\left.^{-1}\right)$. A diversidade na floresta turfosa profunda foi muito baixa $\left(\mathrm{H}^{\prime}=0,82\right.$ nat.ind. $\left.{ }^{-1}\right)$, sendo a menor já registrada para florestas sem perturbação antrópica das regiões sul e sudeste brasileira. A heterogeneidade vegetacional em áreas de floresta contínua, condicionada aos fatores fisiográficos das planícies litorâneas, indica a necessidade de se proteger o maior número de situações ambientais possíveis, objetivando a conservação da biodiversidade in situ.

Key words - Atlantic Rain Forest, tropical peat forest, vegetational mosaic, phytosociology, coastal plains

\section{Introdução}

Os fatores condicionantes dos padrões de riqueza e diversidade da Floresta Atlântica paulista têm sido amplamente discutidos na atualidade (Leitão Filho 1982, 1994, Mantovani 1998). Este bioma tem se confirmado como de grande diversidade e endemismo (Joly et al. 1991), embora sua riqueza total pareça estar abaixo dos

1. Parte da dissertação de mestrado de M. Sztutman.

2. Universidade de São Paulo, Escola Superior de Agricultura "Luiz de Queiroz", Departamento de Ciências Biológicas, Av Pádua Dias 11, Caixa Postal 09, 13418-900 Piracicaba, SP, Brazil.

3. Autor para correspondência: rrr@esalq.usp.br valores encontrados em outras florestas tropicais, como a Amazônica (Tabarelli \& Mantovani 1999). Dentre seus vários blocos florísticos, as formações sobre a unidade geomorfológica das planícies litorâneas estão entre as mais descaracterizadas do Estado de São Paulo, em função da intensa ação antrópica nestas áreas (Consórcio Mata Atlântica 1992). As planícies litorâneas de uma mesma região estão muitas vezes sujeitas a um mesmo clima. Deste modo, os principais fatores determinantes das diferenças florísticas e estruturais de suas comunidades estão ligados às características fisiográficas locais, como a topografia, o substrato e a idade dos depósitos sedimentares (Araujo 1987, Mantovani 1992). 
Dentro da variabilidade fisiográfica das planícies litorâneas destacam-se, por suas características peculiares, os depósitos de turfa (material orgânico parcialmente decomposto). O surgimento e acúmulo da turfa está associado ao preenchimento de lagoas ou de meandros de rios abandonados por material predominantemente vegetal, que, em função do ambiente anóxico, permanece apenas parcialmente decomposto (IPT 1981). As comunidades florestais que aí ocorrem sujeitam-se a um substrato permanentemente encharcado, com diferentes níveis de inundação de acordo com as condições locais. Embora suas características florísticas e ecológicas sejam muito pouco investigadas, têm sido denominadas de forma genérica como florestas turfosas (Waechter 1985, 1990, Ramos Neto 1993, Waechter \& Jarenkow 1998).

$\mathrm{O}$ presente estudo investigou o mosaico vegetacional das planícies litorâneas, com o objetivo principal de descrever a florística, estrutura e fisionomia de duas florestas sobre substrato turfoso e uma sobre solo firme, num trecho contínuo de floresta do Parque Estadual da Campina do Encantado, Município de Pariquera-Açu.

\section{Material e métodos}

O Parque Estadual da Campina do Encantado (PECE), situado no município de Pariquera-Açu (SP) (coordenadas centrais aproximadas de $24^{\circ} 40^{\prime} \mathrm{S}$ e $47^{\circ} 48^{\prime} \mathrm{W}$ ), foi criado em 1994 com cerca de 3.000 ha (São Paulo 1998). Apesar de distar cerca de $20 \mathrm{~km}$ da linha do mar, o PECE está inteiramente inserido na Planície Litorânea de Iguape/ Cananéia, na região costeira do Vale do Rio Ribeira de Iguape.

O clima da região é do tipo Cfa (Köppen), mesotérmico úmido sem estação seca, com pluviosidade média anual de $1.688 \mathrm{~mm}$ (entre os anos de 1962 e 1991), sendo o trimestre de janeiro a março o mais chuvoso e o de junho a agosto o mais seco (São Paulo 1998).

O PECE é rodeado por rios meândricos e possui em seu interior uma enorme turfeira que atinge mais de 5 metros de profundidade nas porções centrais (Sztutman 2000). Seus solos são predominantemente orgânicos álicos, ocorrendo manchas de solo Podzólico Vermelho-Amarelo Álico associadas a morros isolados e solos aluviais junto aos leitos de rios (Lepsch et al. 1998).

As florestas do PECE possuem diferentes fisionomias e estruturas, associadas principalmente ao tipo de solo e às influências hídricas. De modo contrário ao seu entorno, suas florestas permanecem, ainda hoje, bem conservadas em função dos alagamentos periódicos a que estão sujeitas, praticamente impossibilitando o uso das terras para a moradia e para atividades agrícolas (São Paulo 1998). O PECE representa hoje uma das maiores áreas de floresta contínua em bom estado de conservação sobre planícies alagáveis do litoral sudeste brasileiro.

A identificação dos tipos ou unidades florestais a serem amostradas foi efetuada com base na fotointerpretação de fotografias aéreas verticais de 1972 (escala 1:25.000) e 1981 (escala 1:35.000) e verificação da verdade terrestre. Os critérios de escolha para a amostragem das unidades florestas foram i) representar diferentes situações fisiográficas; ii) representar a maior parcela possível da vegetação do PECE; iii) possuir características comuns a outras regiões do litoral sudeste brasileiro; iv) possuir carência de estudos publicados. Deste modo, foram escolhidas para a amostragem fitossociológica uma floresta sobre morrote, uma floresta turfosa rasa e uma floresta turfosa profunda. A floresta sobre morrote caracteriza-se como Floresta Alta do Litoral (Eiten 1970) e situa-se sobre solo Podzólico Vermelho-Amarelo Álico (Lepsch et al. 1998). Possui altitude média de $18 \mathrm{~m}$ e está livre de inundações.

As duas florestas sobre turfeira desenvolvem-se em substrato anóxico e caracterizam-se como Florestas de Restinga (Eiten 1970). A floresta turfosa rasa situa-se sobre depósito de turfa não muito profundo, variando de cerca de 1,5 até de $3 \mathrm{~m}$ de espessura (Sztutman 2000). Está sujeita a alagamentos periódicos e apresenta microcanais de drenagem, onde montículos de substrato emerso atuam como pontos preferenciais de desenvolvimento da vegetação. A floresta turfosa profunda localiza-se na porção central da turfeira do PECE, sobre um depósito com mais de $5 \mathrm{~m}$ de espessura. Embora seu substrato permaneça encharcado durante todo o ano, a água não chega a aflorar em nenhum período, de modo que não se formam microcanais de drenagem (Sztutman 2000). Uma grande peculiaridade desta área é a presença de gás metano estocado no subsolo, passível de ser canalizado para a superfície e queimado mediante um furo com vara no chão, gerando uma chama de até $50 \mathrm{~cm}$.

Foi realizado o levantamento fitossociológico de cada unidade florestal através do método de parcelas contíguas (Mueller-Dombois \& Ellenberg 1974) de $10 \times 10$ m, reunidas em blocos distintos de $1.000 \mathrm{~m}^{2}$ (10 parcelas), totalizando 0,56 ha de área total. A escolha dos pontos de amostragem evitou as zonas de transição entre as unidades florestais, priorizando áreas core de cada uma delas. Em função da interpretação das curvas do esforço amostral, amostrou-se 0,2 ha (dois blocos) na floresta turfosa profunda, 0,3 ha (três blocos) na floresta turfosa rasa e 0,54 ha (três blocos mais um quarto maior, de $2.400 \mathrm{~m}^{2}$ ) na floresta sobre morrote. $\mathrm{O}$ gráfico final do esforço amostral foi construído a partir da média de 50 gráficos, através do programa Estimates (Colwell 1997), onde a ordem das parcelas foi aleatória.

Para cada parcela foram numerados, medidos e identificados todos os indivíduos arbóreos com perímetro do tronco na altura do peito $(1,3 \mathrm{~m}) \geq 15 \mathrm{~cm}$ (DAP $\geq 4,8 \mathrm{~cm}$ ). No caso de troncos ramificados abaixo de 1,3 m, o indivíduo 
foi amostrado caso a soma dos perfilhos acima de $3 \mathrm{~cm}$ de perímetro fosse $\geq 15 \mathrm{~cm}$. Este procedimento foi adotado em função das condições de campo da floresta turfosa profunda, que possui os troncos das árvores muito ramificados e finos desde a base. Caso fossem incluídos somente indivíduos que tivessem ao menos um tronco com o perímetro mínimo de $15 \mathrm{~cm}$, muitos indivíduos do dossel deixariam de ser amostrados. Por outro lado, se o perímetro mínimo de inclusão fosse diminuído, passariam a ser incluídas muitas espécies do subosque da floresta sobre morrote, o que estaria obscurecendo a comparação entre as áreas.

O material botânico foi coletado com auxílio de tesoura de poda alta e estilingue, sendo identificado através de literatura apropriada, comparações nos herbários paulistas SPSF (Instituto Florestal), SP (Instituto de Botânica) e ESA (Departamento de Ciências Biológicas da ESALQ/USP) e envio de materiais para especialistas de diversas famílias.

Para cada unidade florestal estudada foram calculados os parâmetros fitossociológicos comuns em estudos desta natureza (Rodrigues 1988), o índice de diversidade de Shannon (H') e a equabilidade (J') (Pielou 1975).

A fim de comparar floristicamente as unidades vegetacionais estudadas, foi elaborada uma matriz de presença e ausência de espécies e a partir dela construído um dendrograma de similaridade entre todas as parcelas do estudo, com todas as espécies amostradas. Para tanto foi utilizado o índice de similaridade de Jaccard (Pielou 1975) e o método de agrupamento de média de grupo (UPGMA). Também foi calculado o índice de similaridade de Jaccard $\left(\mathrm{J}_{\mathrm{ac}}\right)$ entre a flora de cada comunidade em relação a outros trabalhos fitossociológicos da região sul do estado de São Paulo (Ivanauskas 1997, Melo \& Mantovani 1944, Sugiyama 1998). Os cálculos dos parâmetros quantitativos e a construção do dendrograma foram efetuados através do programa FITOPAC (Shepherd 1995). Foi construído um perfil florestal de $30 \times 5 \mathrm{~m}$ para cada unidade florestal amostrada, onde foram representados apenas os indivíduos amostrados no estudo fitossociológico.

\section{Resultados e Discussão}

Florística - Ao todo, foram amostradas no levantamento fitossociológico, nas três unidades florestais, 144 espécies (tabela 1). Na floresta sobre morrote foi encontrado um total de 112 espécies. A família com maior riqueza foi Myrtaceae, com 27 espécies (24\%), seguida de Lauraceae (11 espécies; 9,8\%), Leguminosae (nove espécies; 8\%), Rubiaceae (seis espécies; 5,4\%) e Chrysobalanaceae, Euphorbiaceae, Moraceae e Sapotaceae (cinco espécies cada; 4,5\%). A floresta turfosa rasa apresentou 46 espécies. De forma análoga à floresta sobre morrote, as duas famílias mais ricas nesta área também foram Myrtaceae, com nove espécies
(19,6\%), e Lauraceae, com sete espécies (15\%), mas com apenas três e duas espécies em comum, respectivamente, com a floresta sobre morrote. Euphorbiaceae e Myrsinaceae seguiram a lista das famílias mais ricas, apresentando três espécies cada $(6,5 \%)$.

A floresta turfosa profunda apresentou apenas cinco espécies, sendo duas pertencentes à família Aquifoliaceae, e Theaceae, Lauraceae e Clusiaceae apresentando uma espécie cada.

Uma nítida diferenciação florística entre essas unidades florestais foi evidenciada através da baixa similaridade de Jaccard encontrada entre as parcelas de estudo em cada área (figura 1). Entre a floresta sobre morrote e a floresta turfosa rasa ocorreram apenas 16 espécies em comum, representando 34,5\% das espécies amostradas na floresta turfosa rasa, e apenas $14,3 \%$ das espécies amostradas na floresta sobre morrote. $\mathrm{O}$ índice de similaridade de Jaccard $\left(\mathrm{J}_{\mathrm{ac}}\right)$ para estas duas florestas foi de 0,109 .

Estas diferenças florísticas estão relacionadas às diferentes formações contribuidoras das floras locais, conforme demonstra as similaridades obtidas para as florestas do PECE em relação a outras da região sul do estado de São Paulo (tabela 2). A floresta sobre morrote apresentou similaridade mais alta com áreas sobre o embasamento cristalino em Pariquera-Açu $\left(\mathrm{J}_{\mathrm{ac}}=0,460\right)$ (Ivanauskas 1997) e em Cananéia $\left(\mathrm{J}_{\mathrm{ac}}=0,266\right)$ (Melo \& Mantovani 1994), e mais baixa com áreas de floresta sobre planícies litorâneas em Cananéia $\left(\mathrm{J}_{\mathrm{ac}}=0,103 \mathrm{e}\right.$ $\left.\mathrm{J}_{\mathrm{ac}}=0,038\right)$ (Sugiyama 1998). Já a floresta turfosa rasa apresentou alta similaridade com as florestas sobre planícies litorâneas de Cananéia $\left(\mathrm{J}_{\mathrm{ac}}=0,328\right.$, $\left.\mathrm{J}_{\mathrm{ac}}=0,309\right)$ (Sugiyama 1998) e baixa similaridade com as florestas sobre embasamento cristalino de Pariquera-Açu $\left(\mathrm{J}_{\mathrm{ac}}=0,088\right)$ (Ivanauskas 1997) e Cananéia $\left(\mathrm{J}_{\mathrm{ac}}=0,043\right)$ (Melo \& Mantovani 1994). Assim, a floresta turfosa rasa possui uma contribuição mais intensa da flora das planícies litorâneas, enquanto que a floresta sobre morrote possui uma contribuição mais intensa da flora dos terrenos cristalinos da baixa encosta da Serra do Mar.

A floresta sobre turfeira profunda apresentou similaridades mais baixas em relação as florestas do PECE e também em relação aos outros estudos (tabela 2), principalmente em função de seu pequeno número de espécies, que influencia o índice de Jaccard. Das suas cinco espécies, nenhuma foi comum à floresta sobre morrote, e quatro foram comuns à floresta turfosa rasa $(80 \%)$. A grande redução da riqueza, associada à alta porcentagem de espécies coocorrentes, demonstra 
Tabela 1. Espécies coletadas em levantamentos fitossociológicos no Parque Estadual da Campina do Encantado, PariqueraAçu, SP: FSM: floresta sobre morrote; FTR: floresta turfosa rasa; FTP: floresta turfosa profunda.

\begin{tabular}{|c|c|c|c|c|}
\hline Família & Espécie & FSM & FTR & FTP \\
\hline ANACARDIACEAE & Tapirira guianensis Aubl. & & $\mathrm{X}$ & \\
\hline \multirow[t]{3}{*}{ ANNONACEAE } & Guatteria australis A. St.-Hil. & & $\mathrm{x}$ & \\
\hline & Rollinia sericea (R.E. Fr) R.E. Fr. & $\mathrm{X}$ & & \\
\hline & Xylopia langsdorffiana A. St.-Hil. \& Tul. & $\mathrm{x}$ & $\mathrm{X}$ & \\
\hline \multirow[t]{3}{*}{ AQUIFOLIACEAE } & Ilex dumosa Reissek & & & $\mathrm{X}$ \\
\hline & Ilex pseudobuxus Reissek & & $\mathrm{X}$ & $\mathrm{x}$ \\
\hline & Ilex theezans Mart. & $\mathrm{X}$ & $\mathrm{x}$ & \\
\hline ARALIACEAE & Didymopanax calvum (Cham.) Decne. \& Planch. & $\mathrm{x}$ & $\mathrm{x}$ & \\
\hline \multirow[t]{3}{*}{ ARECACEAE } & Astrocaryum aculeatissimum (Schott) Burret & $\mathrm{x}$ & & \\
\hline & Euterpe edulis Mart. & $\mathrm{x}$ & $\mathrm{X}$ & \\
\hline & Geonoma schottiana Mart. & & $\mathrm{x}$ & \\
\hline BIGNONIACEAE & Tabebuia cf. alba (Cham.) Sandwith & $\mathrm{X}$ & & \\
\hline BORAGINACEAE & Cordia sellowiana Cham. & $\mathrm{x}$ & & \\
\hline BURSERACEAE & Protium heptaphyllum (Aubl.) Marchand & $\mathrm{x}$ & & \\
\hline \multirow[t]{2}{*}{ CECROPIACEAE } & Cecropia glaziouii Snethl. & $\mathrm{x}$ & & \\
\hline & Pourouma guianensis Aubl. & $\mathrm{X}$ & & \\
\hline CELASTRACEAE & Maytenus robusta Reissek & $\mathrm{x}$ & $\mathrm{X}$ & \\
\hline \multirow[t]{5}{*}{ CHRYSOBALANACEAE } & Hirtella hebeclada Moric. ex DC. & $\mathrm{x}$ & & \\
\hline & Licania cf. kunthiana Hook. f. & $\mathrm{x}$ & & \\
\hline & Licania octandra (Hoffmanns. ex Roem. \& Schult.) Kuntze & $\mathrm{x}$ & & \\
\hline & Parinari brasiliensis (Schott) Hook. f. & $\mathrm{x}$ & & \\
\hline & Parinari excelsa Sabine & $\mathrm{x}$ & & \\
\hline \multirow[t]{3}{*}{ CLUSIACEAE } & Calophyllum brasiliensis Cambess. & & $\mathrm{X}$ & \\
\hline & Clusia criuva Cambess. & & $\mathrm{x}$ & $\mathrm{x}$ \\
\hline & Garcinia gardneriana (Planch. \& Triana) D. Zappi & $\mathrm{X}$ & & \\
\hline COMBRETACEAE & Buchenavia kleinii Exell & $\mathrm{x}$ & & \\
\hline CUNONIACEAE & Weinmannia cf. paulliniifolia Pohl ex Ser. & & $\mathrm{X}$ & \\
\hline \multirow[t]{2}{*}{ CYATHEACEAE } & Trichipteris atrovirens (Lang. \& Fisch.) Tryon & & $\mathrm{X}$ & \\
\hline & Trichipteris corcovadensis (Raddi) Copel. & $\mathrm{X}$ & & \\
\hline \multirow[t]{3}{*}{ ELAEOCARPACEAE } & Sloanea guianensis (Aubl.) Benth. & & & \\
\hline & Sloanea monosperma Vell. & & $\mathrm{X}$ & \\
\hline & Sloanea obtusifolia (Moric.) K. Schum. & $\mathrm{X}$ & & \\
\hline \multirow[t]{6}{*}{ EUPHORBIACEAE } & Alchornea triplinervia (Spreng.) Müll. Arg. & $\mathrm{x}$ & $\mathrm{X}$ & \\
\hline & Aparisthmium cordatum (A. Juss.) Baill. & $\mathrm{x}$ & & \\
\hline & Hyeronima alchorneoides Allemão & $\mathrm{x}$ & & \\
\hline & Maprounea guianensis Aubl. & & $\mathrm{X}$ & \\
\hline & Pausandra morisiana (Casar.) Radlk. & $\mathrm{X}$ & & \\
\hline & Pera glabrata (Schott) Baill. & $\mathrm{x}$ & $\mathrm{X}$ & \\
\hline \multirow[t]{2}{*}{ HUMIRIACEAE } & Humiriastrum dentatum (Casar.) Cuatrec. & $\mathrm{x}$ & & \\
\hline & Vantanea compacta (Schnizl.) Cuatrec. & $\mathrm{x}$ & & \\
\hline \multirow[t]{9}{*}{ LAURACEAE } & Aniba firmula (Nees \& Mart.) Mez & & $\mathrm{X}$ & \\
\hline & Aniba viridis $\mathrm{Mez}$ & $\mathrm{X}$ & & \\
\hline & Cryptocarya moschata Nees & $\mathrm{x}$ & & \\
\hline & Endlicheria paniculata (Spreng.) J.F. Macbr. & $\mathrm{x}$ & $\mathrm{X}$ & \\
\hline & Nectandra aff. psammophila Nees & $\mathrm{x}$ & & \\
\hline & Nectandra nitidula Nees & $\mathrm{x}$ & & \\
\hline & Nectandra oppositifolia Nees & & $\mathrm{X}$ & \\
\hline & Ocotea aciphylla (Ness) Mez & & $\mathrm{x}$ & \\
\hline & Ocotea dispersa (Nees) Mez & $\mathrm{x}$ & & \\
\hline
\end{tabular}


Tabela 1 (cont.)

\begin{tabular}{|c|c|c|c|c|}
\hline Família & Espécie & FSM & FTR & FTP \\
\hline \multirow[t]{7}{*}{ LAURACEAE } & Ocotea elegans $\mathrm{Mez}$ & $\mathrm{X}$ & & \\
\hline & Ocotea glaziovii $\mathrm{Mez}$ & $\mathrm{x}$ & & \\
\hline & Ocotea odorifera (Vell.) Rohwer & $\mathrm{x}$ & & \\
\hline & Ocotea pulchella (Nees) Mez & & $\mathrm{X}$ & $\mathrm{X}$ \\
\hline & Ocotea teleiandra (Meisn.) Mez & $\mathrm{X}$ & & \\
\hline & Ocotea venulosa (Nees) Mez & $\mathrm{X}$ & $\mathrm{X}$ & \\
\hline & Persea venosa Nees \& Mart. ex Ness & & $\mathrm{x}$ & \\
\hline \multicolumn{5}{|l|}{ LEGUMINOSAE } \\
\hline CAESALPINOIDEAE & Copaifera trapezifolia Hayne & $\mathrm{X}$ & & \\
\hline \multicolumn{5}{|l|}{ LEGUMINOSAE } \\
\hline \multirow[t]{5}{*}{ FABOIDEAE } & Andira fraxinifolia Benth. & $\mathrm{X}$ & $\mathrm{X}$ & \\
\hline & Myroxylon peruiferum L. f. & $\mathrm{x}$ & & \\
\hline & Ormosia arborea Harms & $\mathrm{X}$ & & \\
\hline & Pterocarpus rohrii Vahl & $\mathrm{X}$ & & \\
\hline & Zollernia ilicifolia Vogel & $\mathrm{X}$ & & \\
\hline \multicolumn{5}{|l|}{ LEGUMINOSAE } \\
\hline \multirow[t]{3}{*}{ MIMOSOIDEAE } & Inga cf. capitata Desv. & $\mathrm{X}$ & & \\
\hline & Inga sessilis (Vell.) Mart. & $\mathrm{X}$ & & \\
\hline & Inga sp.1 & $\mathrm{X}$ & & \\
\hline MALPIGHIACEAE & Byrsonima ligustrifolia A. Juss. & & $\mathrm{X}$ & \\
\hline MELASTOMATACEAE & Miconia rigidiuscula Cogn. & $\mathrm{X}$ & & \\
\hline \multirow[t]{3}{*}{ MELIACEAE } & Cabralea canjerana (Vell.) Mart. & $\mathrm{x}$ & & \\
\hline & Guarea macrophylla Vahl & $\mathrm{X}$ & & \\
\hline & Trichilia silvatica C. DC. & $\mathrm{X}$ & & \\
\hline MONIMIACEAE & Mollinedia schottiana Perkins & $\mathrm{X}$ & & \\
\hline \multirow[t]{5}{*}{ MORACEAE } & Brosimum cf. glaziovii Taub. & $\mathrm{X}$ & & \\
\hline & Brosimum lactescens (S. Moore) C.C. Berg & $\mathrm{x}$ & & \\
\hline & Ficus gomelleira Kunth \& Bouche ex Kunth & $\mathrm{x}$ & & \\
\hline & Sorocea jureiana Romaniuc & $\mathrm{X}$ & & \\
\hline & Moraceae sp. 1 & $\mathrm{X}$ & & \\
\hline \multirow[t]{2}{*}{ MYRISTICACEAE } & Virola bicuhyba (Schott \& Spreng.) Warb. & $\mathrm{x}$ & & \\
\hline & Virola gardneri Warb. & $\mathrm{X}$ & & \\
\hline \multirow[t]{4}{*}{ MYRSINACEAE } & Cybianthus peruvianus (A. DC.) Miq. & & $\mathrm{X}$ & \\
\hline & Rapanea ferruginea $\mathrm{Mez}$ & & $\mathrm{x}$ & \\
\hline & Rapanea hermogenesii Jung.-Mend. \& Bernacci & $\mathrm{X}$ & & \\
\hline & Rapanea venosa (A. DC.) Mez & & $\mathrm{X}$ & \\
\hline \multirow[t]{15}{*}{ MYRTACEAE } & Blepharocalyx salicifolius (H.B.K.) O. Berg & & $\mathrm{x}$ & \\
\hline & Calyptranthes grandifolia $\mathrm{O}$. Berg & $\mathrm{x}$ & & \\
\hline & Calyptranthes lanceolata $\mathrm{O}$. Berg & $\mathrm{X}$ & & \\
\hline & Calyptranthes strigipes O. Berg & $\mathrm{X}$ & & \\
\hline & Eugenia beaurepaireana (Kiaersk.) D. Legrand & $\mathrm{X}$ & & \\
\hline & Eugenia cerasifolia Miq. & $\mathrm{X}$ & & \\
\hline & Eugenia cuprea (O. Berg) Nied. & $\mathrm{x}$ & & \\
\hline & Eugenia excelsa O. Berg & $\mathrm{x}$ & & \\
\hline & Eugenia neoglomerata Sobral & $\mathrm{X}$ & & \\
\hline & Eugenia neolanceolata Sobral & $\mathrm{X}$ & & \\
\hline & Eugenia oblongata $\mathrm{O}$. Berg & $\mathrm{X}$ & & \\
\hline & Eugenia aff. prasina $\mathrm{O}$. Berg & $\mathrm{x}$ & & \\
\hline & Eugenia stigmatosa DC. & $\mathrm{X}$ & $\mathrm{x}$ & \\
\hline & Eugenia subavenia $\mathrm{O}$. Berg & $\mathrm{x}$ & & \\
\hline & Eugenia umbelliflora $\mathrm{O}$. Berg & & $\mathrm{X}$ & \\
\hline
\end{tabular}


Tabela 1 (cont.)

\begin{tabular}{|c|c|c|c|c|}
\hline Família & Espécie & FSM & FTR & FTP \\
\hline MYRTACEAE & $\begin{array}{l}\text { Eugenia sp. } 1 \\
\text { Gomidesia anacardiifolia (Gardner) O. Berg } \\
\text { Gomidesia fenzliana } \text { O. Berg. } \\
\text { Gomidesia tijucensis (Kiaersk.) D. Legrand } \\
\text { Marlierea eugeniopsoides (Legrand \& Kausel) D. Legrand } \\
\text { Marlierea obscura } \text { O. Berg } \\
\text { Marlierea tomentosa Cambess. } \\
\text { Myrceugenia myrcioides (Cambess.) O. Berg } \\
\text { Myrcia acuminatissima O. Berg } \\
\text { Myrcia bicarinata } \text { (O. Berg) D. Legrand } \\
\text { Myrcia formosiana DC. } \\
\text { Myrcia heringii D. Legrand } \\
\text { Myrcia cf. macrocarpa Kiaersk. } \\
\text { Myrcia multiflora (Lam.) DC. } \\
\text { Myrcia pubipetala Miq. } \\
\text { Myrciaria floribunda } \text { (West ex Willd.) O. Berg } \\
\text { Psidium cattleyanum Sabine } \\
\text { Myrtaceae sp.1 }\end{array}$ & $\begin{array}{l}\mathrm{X} \\
\mathrm{X} \\
\mathrm{X} \\
\mathrm{X} \\
\mathrm{X}\end{array}$ & $\begin{array}{l}\mathrm{x} \\
\mathrm{x}\end{array}$ & \\
\hline $\begin{array}{l}\text { NYCTAGINACEAE } \\
\text { OCHNACEAE } \\
\text { OLACACEAE }\end{array}$ & $\begin{array}{l}\text { Guapira opposita (Vell.) Reitz } \\
\text { Ouratea parviflora (DC.) Baill. } \\
\text { Heisteria silvianii Schwacke } \\
\text { Tetrastylidium grandifolium (Baill.) Sleumer }\end{array}$ & $\begin{array}{l}X \\
X \\
X \\
X\end{array}$ & $\mathrm{x}$ & \\
\hline $\begin{array}{l}\text { PODOCARPACEAE } \\
\text { PROTEACEAE } \\
\text { QUINACEAE } \\
\text { ROSACEAE }\end{array}$ & $\begin{array}{l}\text { Podocarpus sellowii Klotzsch } \\
\text { Euplassa legalis (Vell.) I.M. Johnson } \\
\text { Quiina glaziovii Engl. } \\
\text { Prunus myrtifolia (L.) Urb. }\end{array}$ & $\begin{array}{l}\mathrm{X} \\
\mathrm{X} \\
\mathrm{X}\end{array}$ & $\mathrm{x}$ & \\
\hline RUBIACEAE & $\begin{array}{l}\text { Amaioua intermedia Mart. } \\
\text { Faramea montevidensis (Cham. \& Schltdl.) DC. } \\
\text { Psychotria mapoureoides DC. } \\
\text { Rudgea recurva Müll. Arg. } \\
\text { Rubiaceae sp. } 1 \\
\text { Rubiaceae sp. } 2\end{array}$ & $\begin{array}{l}\mathrm{X} \\
\mathrm{x} \\
\mathrm{X} \\
\mathrm{X} \\
\mathrm{X} \\
\mathrm{X}\end{array}$ & $\mathrm{x}$ & \\
\hline $\begin{array}{l}\text { SABIACEAE } \\
\text { SAPINDACEAE }\end{array}$ & $\begin{array}{l}\text { Meliosma sellowii Urb. } \\
\text { Cupania oblongifolia Mart. } \\
\text { Matayba elaeagnoides Radlk. } \\
\text { Matayba juglandifolia (Cambess.) Radlk. }\end{array}$ & $\begin{array}{l}\mathrm{X} \\
\mathrm{X} \\
\mathrm{X}\end{array}$ & $\mathrm{x}$ & \\
\hline SAPOTACEAE & $\begin{array}{l}\text { Diploon cuspidatum (Hoehne) Cronquist } \\
\text { Ecclinusa ramiflora Mart. } \\
\text { Manilkara subsericea (Mart.) Dubard } \\
\text { Pouteria beaurepairei (Glaz. \& Raunk.) Baehni } \\
\text { Pouteria caimito (Ruiz \& Pavon) Radlk. } \\
\text { Pouteria psammophila (Mart.) Radlk. }\end{array}$ & $\begin{array}{l}\mathrm{x} \\
\mathrm{x} \\
\mathrm{x} \\
\mathrm{X} \\
\mathrm{x}\end{array}$ & $\mathrm{x}$ & \\
\hline $\begin{array}{l}\text { STYRACACEAE } \\
\text { SYMPLOCACEAE }\end{array}$ & $\begin{array}{l}\text { Styrax glabratum Spreng. } \\
\text { Symplocos trachycarpa Brand } \\
\text { Symplocos variabilis Mart. ex Miq. }\end{array}$ & $\begin{array}{l}\mathrm{X} \\
\mathrm{X}\end{array}$ & $\mathrm{x}$ & \\
\hline THEACEAE & Ternstroemia brasiliensis Cambess. & & $\mathrm{X}$ & $\mathrm{X}$ \\
\hline
\end{tabular}




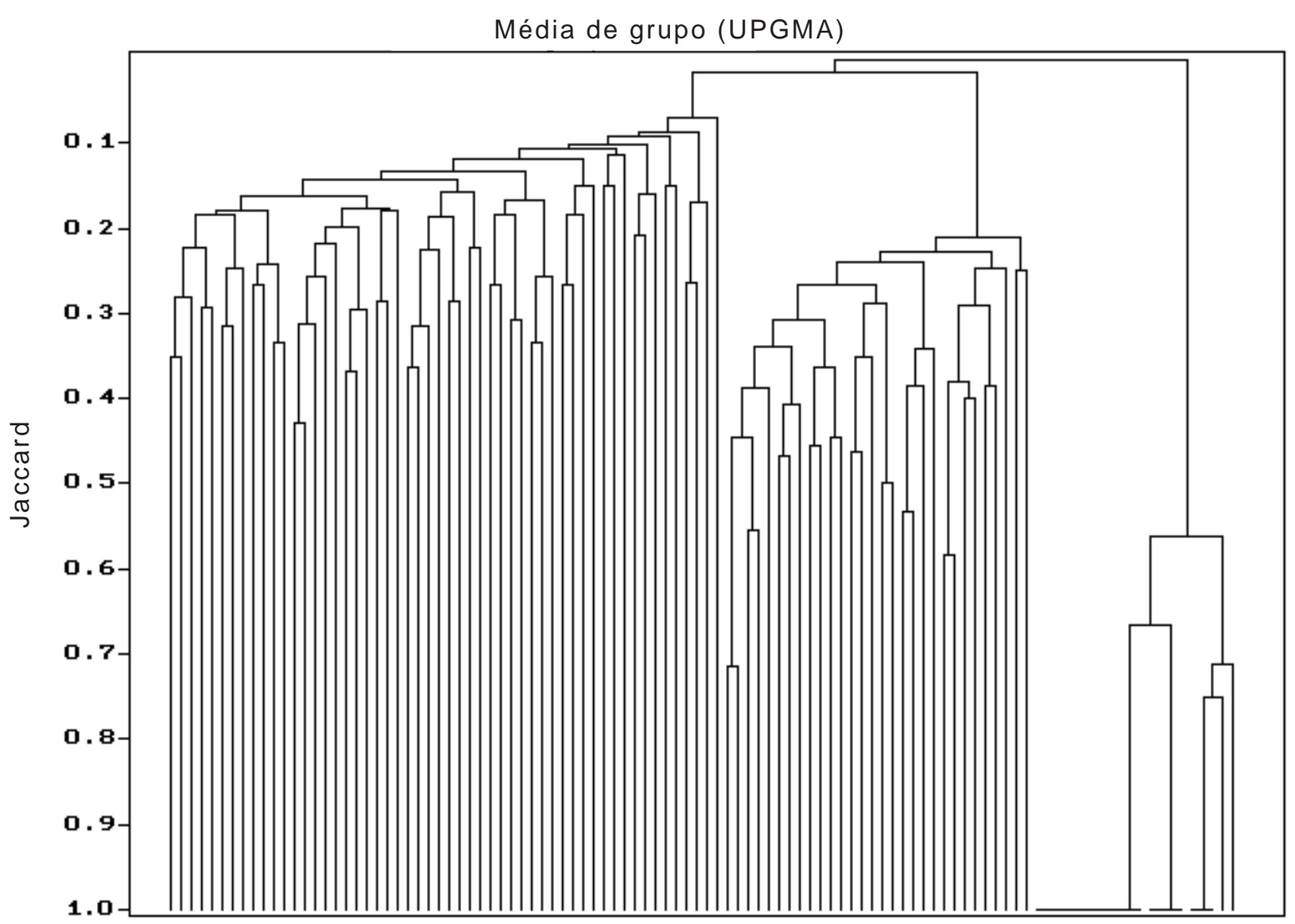

Figura 1. Dendrograma de similaridade de Jaccard com dados de presença e ausência de espécies nas parcelas de estudo fitossociológico, no Parque Estadual da Campina do Encantado, Pariquera-Açu/SP, agrupadas pelo método de média de grupo (UPGMA). FSM: parcelas em floresta sobre morrote; FTR: parcelas em floresta turfosa rasa; FTP: parcelas em floresta turfosa profunda.

Tabela 2. Similaridades de Jaccard entre o total de espécies amostrados no Parque Estadual da Campina do Encantado e em outros estudos fitossociológicos da região sul do estado de São Paulo. FSM: floresta sobre morrote do PECE; FTR: floresta turfosa rasa do PECE; FTP: floresta turfosa profunda do PECE; FEB 1: Ivanauskas 1997, floresta sobre embasamento cristalino, Pariquera-Açu, critério de inclusão DAP $\geq 4,8 \mathrm{~cm}$; FEB 2: Melo \& Mantovani 1994, floresta sobre embasamento cristalino, Cananéia, critério de inclusão DAP $\geq 2,5 \mathrm{~cm}$; FPL 1: Sugiyama 1998, floresta sobre planície litorânea, Cananéia, critério de inclusão DAP $\geq 2,5$; FPL 2: Sugiyama 1998, floresta sobre planície litorânea, Cananéia, critério de inclusão DAP $\geq 1,6$.

\begin{tabular}{lllllll}
\hline & FSM & FTR & FTP & FEB 1 & FEB 2 & FPL 1 \\
\hline FTR & 0,109 & & & & & \\
FTP & 0 & 0,083 & & & & \\
FEB 1 & 0,456 & 0,088 & 0 & & & \\
FEB 2 & 0,266 & 0,043 & 0,013 & 0,317 & & \\
FPL 1 & 0,103 & 0,328 & 0,070 & 0,068 & 0,074 & \\
FPL 2 & 0,038 & 0,309 & 0,118 & 0,026 & 0,028 & 0,371 \\
\hline
\end{tabular}

que existe uma seletividade de espécies da floresta turfosa rasa para a floresta turfosa profunda. Deste modo, compreende-se que estas comunidades representam dois subtipos florestais de uma mesma formação influenciada pela flora das planícies litorâneas, ocorrendo, no entanto, em diferentes condições seletivas de um gradiente ambiental.

Estrutura fitossociológica e fisionômica - As curvas do coletor mostram uma grande tendência a estabilidade para a floresta turfosa profunda. Para a floresta turfosa rasa, a mesma tendência se repete, porém, com uma inclinação da curva ligeiramente mais ascendente. Por fim, na floresta sobre morrote foi observada apenas uma certa tendência de estabilidade da curva (figura 2). Para a finalidade de caracterização e comparação das comunidades, considerou-se suficiente a amostragem atingida nas três áreas.

A floresta turfosa profunda, apresentou elevada densidade (2.730 indivíduos.ha ${ }^{-1}$ ) e baixa área basal $\left(19,2 \mathrm{~m}^{2} \cdot \mathrm{ha}^{-1}\right)$, enquanto a floresta sobre morrote 


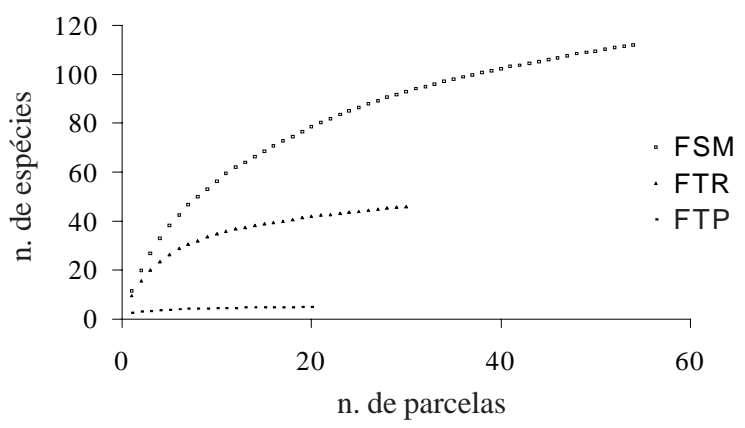

Figura 2. Curvas do número de espécies pelo número de parcelas do estudo fitossociológico, no Parque Estadual da Campina do Encantado, Pariquera-Açu/SP. FSM = floresta sobre morrote; FTR = floresta turfosa rasa; FTP = floresta turfosa profunda.

mostrou baixa densidade (1.422 indivíduos.ha $\left.{ }^{-1}\right)$ e elevada área basal $\left(39,3 \mathrm{~m}^{2} \cdot \mathrm{ha}^{-1}\right)$. A floresta turfosa rasa apresentou valores intermediários entre estes dois tipos vegetacionais, com densidade de 1.730 indivíduos.ha $^{-1}$ e área basal de $27,7 \mathrm{~m}^{2} \cdot \mathrm{ha}^{-1}$. Também foram evidentes as diferenças de altura entre as florestas, que decrescem de forma acentuada da floresta sobre morrote para a floresta turfosa rasa e desta para a floresta turfosa profunda (figura 3).

O topo da floresta sobre morrote variou de 18 a 25 $\mathrm{m}$ (figura 3), com emergentes ocasionalmente atingindo $30 \mathrm{~m}$, não representadas no perfil. A espécie mais conspícua do levantamento fitossociológico foi Euterpe edulis, que obteve o maior VI $(17,4)$, com destaque especialmente da densidade e freqüência relativas (tabela 3). O mesmo padrão de destaque foi encontrado para uma outra palmeira, Astrocaryum aculeatissimum, que ocupou a $3^{\text {a }}$ posição de VI $(13,12)$, lembrando que nenhuma destas duas espécies atinge o dossel. Dentre as espécies que atingem o topo da floresta destacou-se Tetrastylidium grandifolium, Diploon cuspidatum, e Virola gardneri, que ocuparam a $2^{\mathrm{a}}, 4^{\mathrm{a}}$ e $6^{\mathrm{a}}$ posições, respectivamente, na lista de espécie de maiores VI, através de altos valores de dominância relativa e valores intermediários de freqüência e densidade relativas (tabela 3). Além destas, também foram comuns no dossel Sloanea guianensis, Cryptocarya moschata, Matayba juglandifolia, Cupania oblongifolia, dentre outras. As emergentes mais comuns foram Sloanea obtusifolia, Buchenavia kleinii e Ficus gomelleira, que assumiram a 5aㅡ, 7a e $8^{\underline{a}}$ posições da lista, respectivamente, através de elevados valores de dominância e baixos valores de frequiência e densidade relativas. Do total de espécies amostrado neste tipo florestal, 15
$(13,5 \%)$ compuseram $50 \%$ do VI, enquanto que 30 (27\%) obtiveram apenas um indivíduo (tabela 3 ).

Na floresta turfosa rasa, o topo do dossel variou de 10 a $17 \mathrm{~m}$, possuindo trechos bastante abertos (figura 3). Emergentes foram comuns e atingiram até $21 \mathrm{~m}$, embora não estejam representadas no perfil. A espécie de maior VI foi Tapirira guianensis, que se destacou na comunidade através de seus expressivos valores de dominância, frequiência e densidade relativas (tabela 4). Também foram conspícuas Nectandra oppositifolia (3a posição em VI), com destaque para a dominância relativa, e Eugenia umbelliflora e Alchornea triplinervia, (4 ${ }^{\mathrm{a}}$ e $5^{\mathrm{a}}$ posições de VI), com valores relativamente elevados de dominância, freqüência e densidade relativas. Dentre as espécies que apresentaram alto valor de VI, encontram-se algumas que não atingem o dossel, como Myrcia acuminatissima, que obteve a $2^{\mathrm{a}}$ posição, com destaque para a freqüência e densidade relativas e, também, Rapanea venosa e Guatteria australis, que ocuparam os $7^{\circ}$ e $8^{\circ}$ lugares, respectivamente. Outras espécies de destaque da comunidade, e que atingem o dossel, são Pouteria beaurepairei, Psidium cattleyanum, Gomidesia fenzliana, Pera glabrata e Myrcia multiflora. Das 46 espécies encontradas nesta comunidade, $6(13,0 \%)$ totalizaram $50 \%$ do VI, e $11(23,9 \%)$ apresentaram apenas um indivíduo (tabela 4).

A floresta turfosa profunda apresentou um dossel contínuo e bem definido com altura variável de 4,5 a $7 \mathrm{~m}$ (figura 3). Os indivíduos deste tipo florestal chegaram a apresentar mais de 30 ramificações, crescendo de forma tortuosa e criando uma fisionomia peculiar à esta floresta. Das cinco espécies ocorrentes nesta comunidade, Ternstroemia brasiliensis e Ilex pseudobuxus concentraram $97 \%$ dos indivíduos amostrados, resultando em elevados valores de VI (137,52 e 137,06 respectivamente). T. brasiliensis apresentou uma dominância relativa mais elevada que I. pseudobuxus, situação que se inverteu para a densidade relativa (tabela 5). As outras espécies tiveram uma ocorrência apenas ocasional. Ocotea pulchella apresentou dois indivíduos localizados em uma mesma parcela e que alcançaram o dossel; Ilex dumosa apresentou seis indivíduos, na maioria de pequeno porte e ocupando o subdossel; Clusia criuva obteve sete indivíduos ocorrentes exclusivamente no subdossel.

Riqueza e diversidade - A tabela 6 apresenta um resumo dos resultados obtidos para os três tipos vegetacionais estudados. A floresta sobre morrote, com 112 espécies, apresentou altos valores de diversidade e equabilidade 


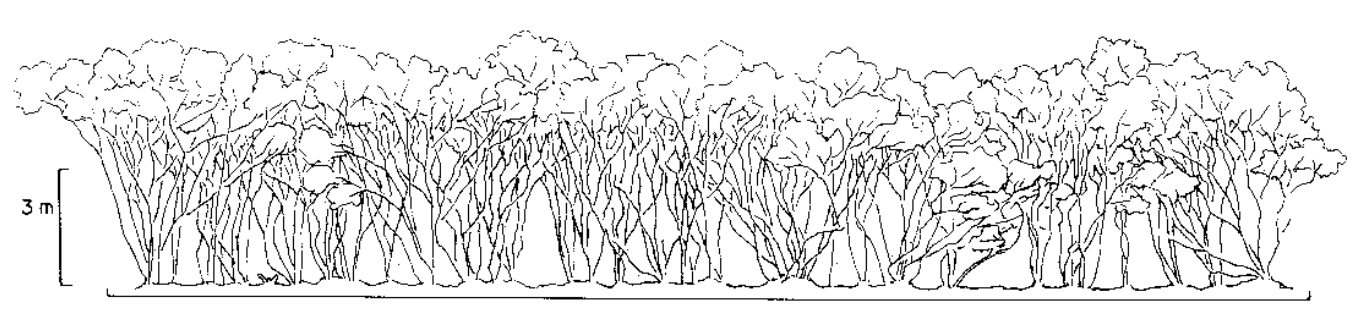

A
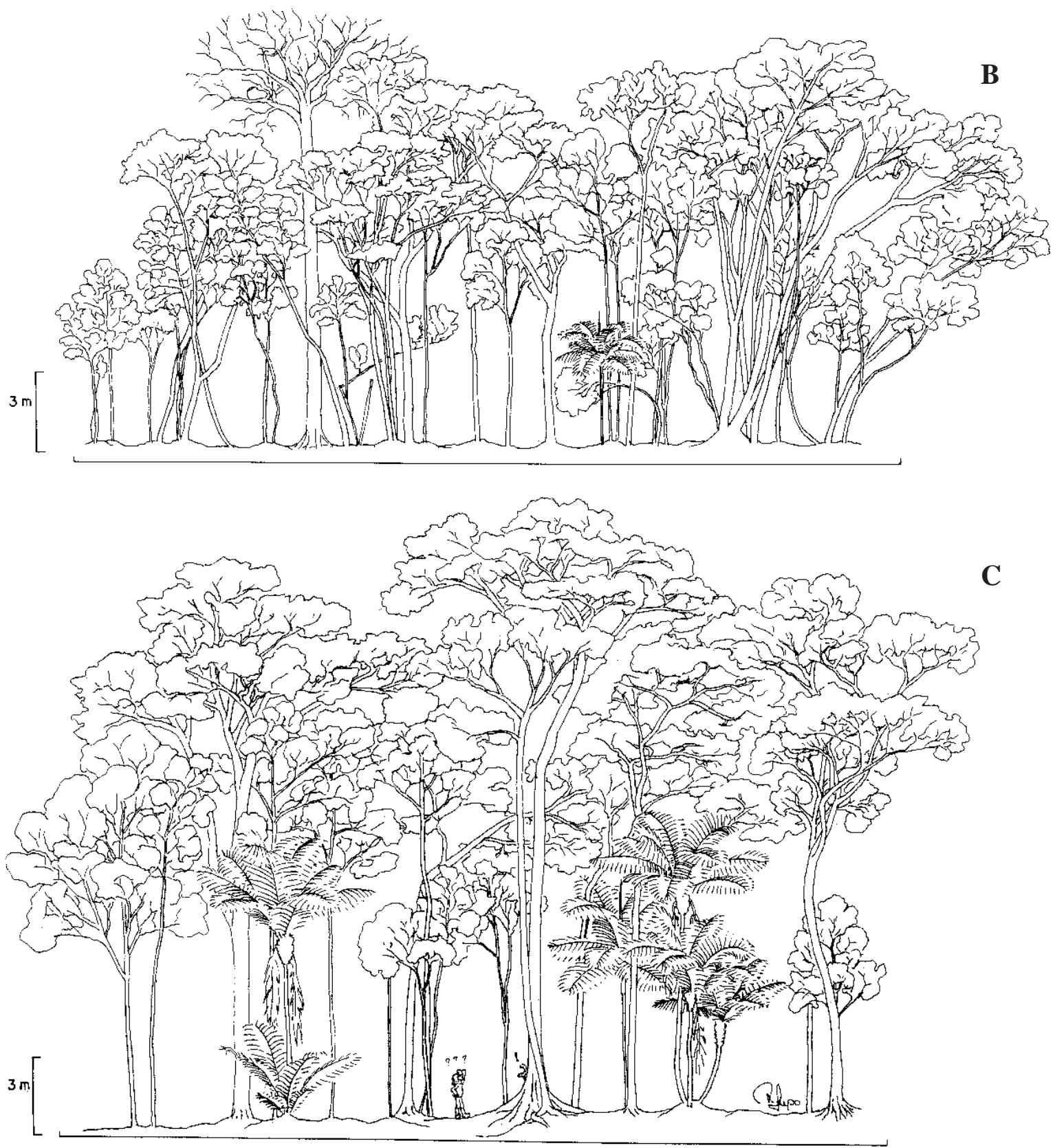

Figura 3. Perfis florestais de $30 \times 5$ m, no Parque Estadual da Campina do Encantado, Pariquera-Açu/SP. A: floresta turfosa profunda; $\mathrm{B}$ : floresta turfosa rasa; $\mathrm{C}$ : floresta sobre morrote. 
Tabela 3. Espécies amostradas em levantamento fitossociológico na floresta sobre morrote, no Parque Estadual da Campina do Encantado, Pariquera-Açu (SP), em ordem decrescente de VI. Ind: número de indivíduos; Fr.A.: freqüência absoluta; Den.A.: densidade absoluta; Do.A.: dominância absoluta; Fr.R.: frequiência relativa; Den.R.: densidade relativa; Do.R.: dominância relativa; VI: índice de valor de importância; VC: índice de valor de cobertura.

\begin{tabular}{|c|c|c|c|c|c|c|c|c|c|c|}
\hline & Espécie & Ind & Fr.A. & Den.A & Do.A. & Fr.R. & Den.R. & Do.R. & $\mathrm{VI}$ & $\mathrm{VC}$ \\
\hline 1 & Euterpe edulis & 77 & 72,2 & 142,6 & 0,501 & 6,43 & 10,03 & 1,28 & 17,73 & 11,30 \\
\hline 2 & Tetrastylidium grandifolium & 29 & 37,0 & 53,7 & 4,093 & 3,29 & 3,78 & 10,42 & 17,49 & 14,20 \\
\hline 3 & Astrocaryum aculeatissimum & 47 & 59,3 & 87,0 & 0,780 & 5,27 & 6,12 & 1,99 & 13,38 & 8,11 \\
\hline 4 & Diploon cuspidatum & 21 & 37,0 & 38,9 & 2,786 & 3,29 & 2,73 & 7,09 & 13,12 & 9,83 \\
\hline 5 & Sloanea obtusifolia & 12 & 18,5 & 22,2 & 3,417 & 1,65 & 1,56 & 8,70 & 11,91 & 10,26 \\
\hline 6 & Virola gardneri & 11 & 13,0 & 20,4 & 2,840 & 1,15 & 1,43 & 7,23 & 9,82 & 8,66 \\
\hline 7 & Buchenavia kleinii & 7 & 9,3 & 13,0 & 3,118 & 0,82 & 0,91 & 7,94 & 9,67 & 8,85 \\
\hline 8 & Ficus gomelleira & 1 & 1,9 & 1,9 & 3,424 & 0,16 & 0,13 & 8,72 & 9,01 & 8,85 \\
\hline 9 & Sloanea guianensis & 20 & 25,9 & 37,0 & 1,519 & 2,31 & 2,60 & 3,87 & 8,78 & 6,47 \\
\hline 10 & Calyptranthes grandifolia & 32 & 37,0 & 59,3 & 0,387 & 3,29 & 4,17 & 0,98 & 8,45 & 5,15 \\
\hline 11 & Rudgea recurva & 25 & 35,2 & 46,3 & 0,211 & 3,13 & 3,26 & 0,54 & 6,92 & 3,79 \\
\hline 12 & Faramea montevidensis & 23 & 33,3 & 42,6 & 0,271 & 2,97 & 2,99 & 0,69 & 6,65 & 3,68 \\
\hline 13 & Cryptocarya moschata & 14 & 24,1 & 25,9 & 0,922 & 2,14 & 1,82 & 2,35 & 6,31 & 4,17 \\
\hline 14 & Calyptranthes strigipes & 20 & 25,9 & 37,0 & 0,470 & 2,31 & 2,60 & 1,20 & 6,11 & 3,80 \\
\hline 15 & Brosimum glaziovii & 13 & 24,1 & 24,1 & 0,684 & 2,14 & 1,69 & 1,74 & 5,57 & 3,43 \\
\hline 16 & Matayba juglandifolia & 14 & 22,2 & 25,9 & 0,598 & 1,98 & 1,82 & 1,52 & 5,32 & 3,34 \\
\hline 17 & Mollinedia schottiana & 17 & 27,8 & 31,5 & 0,154 & 2,47 & 2,21 & 0,39 & 5,08 & 2,61 \\
\hline 18 & Gomidesia spectabilis & 18 & 25,9 & 33,3 & 0,167 & 2,31 & 2,34 & 0,42 & 5,07 & 2,77 \\
\hline 19 & Xylopia langsdorffiana & 16 & 25,9 & 29,6 & 0,184 & 2,31 & 2,08 & 0,47 & 4,86 & 2,55 \\
\hline 20 & Cupania oblongifolia & 11 & 18,5 & 20,4 & 0,659 & 1,65 & 1,43 & 1,68 & 4,76 & 3,11 \\
\hline 21 & Psychotria mapoureoides & 12 & 16,7 & 22,2 & 0,562 & 1,48 & 1,56 & 1,43 & 4,48 & 2,99 \\
\hline 22 & Myrtaceae sp.1 & 16 & 22,2 & 29,6 & 0,108 & 1,98 & 2,08 & 0,28 & 4,34 & 2,36 \\
\hline 23 & Marlierea obscura & 13 & 22,2 & 24,1 & 0,221 & 1,98 & 1,69 & 0,56 & 4,23 & 2,25 \\
\hline 24 & Myrcia heringii & 15 & 22,2 & 27,8 & 0,089 & 1,98 & 1,95 & 0,23 & 4,16 & 2,18 \\
\hline 25 & Licania octandra & 12 & 20,4 & 22,2 & 0,244 & 1,81 & 1,56 & 0,62 & 4,00 & 2,18 \\
\hline 26 & Myrceugenia myrcioides & 14 & 16,7 & 25,9 & 0,150 & 1,48 & 1,82 & 0,38 & 3,69 & 2,21 \\
\hline 27 & Gomidesia tijucensis & 9 & 16,7 & 16,7 & 0,377 & 1,48 & 1,17 & 0,96 & 3,61 & 2,13 \\
\hline 28 & Ecclinusa ramiflora & 10 & 16,7 & 18,5 & 0,269 & 1,48 & 1,30 & 0,68 & 3,47 & 1,99 \\
\hline 29 & Manilkara subsericea & 2 & 3,7 & 3,7 & 1,069 & 0,33 & 0,26 & 2,72 & 3,31 & 2,98 \\
\hline 30 & Aparisthmium cordatum & 13 & 14,8 & 24,1 & 0,111 & 1,32 & 1,69 & 0,28 & 3,29 & 1,98 \\
\hline 31 & Pourouma guianensis & 6 & 9,3 & 11,1 & 0,623 & 0,82 & 0,78 & 1,59 & 3,19 & 2,37 \\
\hline 32 & Ilex theezans & 10 & 11,1 & 18,5 & 0,331 & 0,99 & 1,30 & 0,84 & 3,13 & 2,15 \\
\hline 33 & Brosimum lactescens & 3 & 5,6 & 5,6 & 0,766 & 0,49 & 0,39 & 1,95 & 2,84 & 2,34 \\
\hline 34 & Eugenia subavenia & 9 & 14,8 & 16,7 & 0,085 & 1,32 & 1,17 & 0,22 & 2,71 & 1,39 \\
\hline 35 & Virola bicuhyba & 5 & 9,3 & 9,3 & 0,482 & 0,82 & 0,65 & 1,23 & 2,70 & 1,88 \\
\hline 36 & Ocotea odorifera & 4 & 7,4 & 7,4 & 0,525 & 0,66 & 0,52 & 1,34 & 2,51 & 1,86 \\
\hline 37 & Parinari excelsa & 2 & 3,7 & 3,7 & 0,629 & 0,33 & 0,26 & 1,60 & 2,19 & 1,86 \\
\hline 38 & Trichilia silvatica & 7 & 13,0 & 13,0 & 0,042 & 1,15 & 0,91 & 0,11 & 2,17 & 1,02 \\
\hline 39 & Alchornea triplinervia & 1 & 1,9 & 1,9 & 0,733 & 0,16 & 0,13 & 1,87 & 2,16 & 2,00 \\
\hline 40 & Cecropia glaziouii & 9 & 5,6 & 16,7 & 0,168 & 0,49 & 1,17 & 0,43 & 2,09 & 1,60 \\
\hline 41 & Pouteria psammophila & 7 & 9,3 & 13,0 & 0,121 & 0,82 & 0,91 & 0,31 & 2,04 & 1,22 \\
\hline 42 & Calyptranthes lanceolata & 6 & 11,1 & 11,1 & 0,070 & 0,99 & 0,78 & 0,18 & 1,95 & 0,96 \\
\hline 43 & Ocotea elegans & 5 & 9,3 & 9,3 & 0,180 & 0,82 & 0,65 & 0,46 & 1,93 & 1,11 \\
\hline 44 & Tabebuia cf. alba & 4 & 7,4 & 7,4 & 0,276 & 0,66 & 0,52 & 0,70 & 1,88 & 1,22 \\
\hline 45 & Eugenia beaurepaireana & 5 & 7,4 & 9,3 & 0,200 & 0,66 & 0,65 & 0,51 & 1,82 & 1,16 \\
\hline 46 & Didymopanax calvum & 5 & 9,3 & 9,3 & 0,106 & 0,82 & 0,65 & 0,27 & 1,75 & 0,92 \\
\hline 47 & Myrciaria floribunda & 3 & 5,6 & 5,6 & 0,319 & 0,49 & 0,39 & 0,81 & 1,70 & 1,20 \\
\hline 48 & Maytenus robusta & 4 & 7,4 & 7,4 & 0,189 & 0,66 & 0,52 & 0,48 & 1,66 & 1,00 \\
\hline
\end{tabular}


Tabela 3 (cont.)

\begin{tabular}{|c|c|c|c|c|c|c|c|c|c|c|}
\hline & Espécie & Ind & Fr.A. & Den.A & Do.A. & Fr.R. & Den.R. & Do.R. & VI & $\mathrm{VC}$ \\
\hline 49 & Cabralea canjerana & 6 & 7,4 & 11,1 & 0,075 & 0,66 & 0,78 & 0,19 & 1,63 & 0,97 \\
\hline 50 & Marlierea tomentosa & 5 & 9,3 & 9,3 & 0,062 & 0,82 & 0,65 & 0,16 & 1,63 & 0,81 \\
\hline 51 & Garcinia gardneriana & 5 & 9,3 & 9,3 & 0,056 & 0,82 & 0,65 & 0,14 & 1,62 & 0,79 \\
\hline 52 & Ocotea venulosa & 4 & 7,4 & 7,4 & 0,156 & 0,66 & 0,52 & 0,40 & 1,58 & 0,92 \\
\hline 53 & Trichipteris corcovadensis & 5 & 9,3 & 9,3 & 0,040 & 0,82 & 0,65 & 0,10 & 1,58 & 0,75 \\
\hline 54 & Cordia sellowiana & 4 & 7,4 & 7,4 & 0,147 & 0,66 & 0,52 & 0,37 & 1,55 & 0,90 \\
\hline 55 & Symplocos variabilis & 4 & 7,4 & 7,4 & 0,058 & 0,66 & 0,52 & 0,15 & 1,33 & 0,67 \\
\hline 56 & Pausandra morisiana & 5 & 5,6 & 9,3 & 0,065 & 0,49 & 0,65 & 0,17 & 1,31 & 0,82 \\
\hline 57 & Eugenia excelsa & 4 & 7,4 & 7,4 & 0,039 & 0,66 & 0,52 & 0,10 & 1,28 & 0,62 \\
\hline 58 & Heisteria silvianii & 3 & 5,6 & 5,6 & 0,121 & 0,49 & 0,39 & 0,31 & 1,19 & 0,70 \\
\hline 59 & Copaifera trapezifolia & 3 & 5,6 & 5,6 & 0,106 & 0,49 & 0,39 & 0,27 & 1,15 & 0,66 \\
\hline 60 & Myroxylon peruiferum & 2 & 1,9 & 3,7 & 0,246 & 0,16 & 0,26 & 0,63 & 1,05 & 0,89 \\
\hline 61 & Nectandra aff. psammophila & 2 & 3,7 & 3,7 & 0,176 & 0,33 & 0,25 & 0,31 & 1,04 & 0,22 \\
\hline 62 & Pera glabrata & 3 & 5,6 & 5,6 & 0,052 & 0,49 & 0,39 & 0,13 & 1,02 & 0,52 \\
\hline 63 & Eugenia neoglomerata & 3 & 5,6 & 5,6 & 0,026 & 0,49 & 0,39 & 0,07 & 0,95 & 0,46 \\
\hline 64 & Ocotea dispersa & 3 & 5,6 & 5,6 & 0,025 & 0,49 & 0,39 & 0,06 & 0,95 & 0,45 \\
\hline 65 & Rollinia sericea & 2 & 3,7 & 3,7 & 0,138 & 0,33 & 0,26 & 0,35 & 0,94 & 0,61 \\
\hline 66 & Eugenia cerasiflora & 3 & 5,6 & 5,6 & 0,016 & 0,49 & 0,39 & 0,04 & 0,92 & 0,43 \\
\hline 67 & Hirtella hebeclada & 3 & 5,6 & 5,6 & 0,016 & 0,49 & 0,39 & 0,04 & 0,92 & 0,43 \\
\hline 68 & Myrcia pubipetala & 2 & 3,7 & 3,7 & 0,110 & 0,33 & 0,26 & 0,28 & 0,87 & 0,54 \\
\hline 69 & Ocotea glaziovii & 1 & 1,9 & 1,9 & 0,216 & 0,16 & 0,13 & 0,55 & 0,84 & 0,68 \\
\hline 70 & Vantanea compacta & 2 & 3,7 & 3,7 & 0,055 & 0,33 & 0,26 & 0,14 & 0,73 & 0,40 \\
\hline 71 & Inga sessilis & 2 & 3,7 & 3,7 & 0,055 & 0,33 & 0,26 & 0,14 & 0,73 & 0,40 \\
\hline 72 & Euplassa legalis & 2 & 3,7 & 3,7 & 0,049 & 0,33 & 0,26 & 0,12 & 0,71 & 0,39 \\
\hline 73 & Prunus myrtifolia & 2 & 3,7 & 3,7 & 0,044 & 0,33 & 0,26 & 0,11 & 0,70 & 0,37 \\
\hline 74 & Symplocos trachycarpa & 2 & 3,7 & 3,7 & 0,024 & 0,33 & 0,26 & 0,06 & 0,65 & 0,32 \\
\hline 75 & Pterocarpus rohrii & 2 & 3,7 & 3,7 & 0,022 & 0,33 & 0,26 & 0,06 & 0,65 & 0,32 \\
\hline 76 & Eugenia neolanceolata & 2 & 3,7 & 3,7 & 0,020 & 0,33 & 0,26 & 0,05 & 0,64 & 0,31 \\
\hline 77 & Inga capitata & 2 & 3,7 & 3,7 & 0,018 & 0,33 & 0,26 & 0,04 & 0,63 & 0,31 \\
\hline 78 & Gomidesia anacardiifolia & 2 & 3,7 & 3,7 & 0,018 & 0,33 & 0,26 & 0,04 & 0,63 & 0,30 \\
\hline 79 & Licania cf. kunthiana & 2 & 3,7 & 3,7 & 0,015 & 0,33 & 0,26 & 0,04 & 0,63 & 0,30 \\
\hline 80 & Sorocea jureiana & 2 & 3,7 & 3,7 & 0,014 & 0,33 & 0,26 & 0,04 & 0,63 & 0,30 \\
\hline 81 & Ouratea parviflora & 2 & 3,7 & 3,7 & 0,013 & 0,33 & 0,26 & 0,03 & 0,62 & 0,29 \\
\hline 82 & Marlierea eugeniopsoides & 2 & 3,7 & 3,7 & 0,009 & 0,33 & 0,26 & 0,02 & 0,61 & 0,28 \\
\hline 83 & Hyeronima alchorneoides & 1 & 1,9 & 1,9 & 0,125 & 0,16 & 0,13 & 0,32 & 0,61 & 0,45 \\
\hline 84 & Parinari brasiliensis & 2 & 3,7 & 3,7 & 0,007 & 0,33 & 0,26 & 0,02 & 0,61 & 0,28 \\
\hline 85 & Amaioua intermedia & 1 & 1,9 & 1,9 & 0,109 & 0,16 & 0,13 & 0,28 & 0,57 & 0,41 \\
\hline 86 & Protium heptaphyllum & 1 & 1,9 & 1,9 & 0,072 & 0,16 & 0,13 & 0,18 & 0,48 & 0,31 \\
\hline 87 & Myrcia cf macrocarpa & 1 & 1,9 & 1,9 & 0,066 & 0,16 & 0,13 & 0,17 & 0,46 & 0,30 \\
\hline 88 & Nectandra nitidula & 1 & 1,9 & 1,9 & 0,062 & 0,16 & 0,13 & 0,16 & 0,45 & 0,29 \\
\hline 89 & Humiriastrum dentatum & 1 & 1,9 & 1,9 & 0,046 & 0,16 & 0,13 & 0,12 & 0,41 & 0,25 \\
\hline 90 & Aniba viridis & 1 & 1,9 & 1,9 & 0,041 & 0,16 & 0,13 & 0,11 & 0,40 & 0,24 \\
\hline 91 & Pouteria caimito & 1 & 1,9 & 1,9 & 0,027 & 0,16 & 0,13 & 0,07 & 0,36 & 0,20 \\
\hline 92 & Eugenia sp.1 & 1 & 1,9 & 1,9 & 0,022 & 0,16 & 0,13 & 0,06 & 0,35 & 0,19 \\
\hline 93 & Eugenia stigmatosa & 1 & 1,9 & 1,9 & 0,019 & 0,16 & 0,13 & 0,05 & 0,34 & 0,18 \\
\hline 94 & Rapanea hermogenesii & 1 & 1,9 & 1,9 & 0,017 & 0,16 & 0,13 & 0,04 & 0,34 & 0,17 \\
\hline 95 & Rubiaceae sp.1 & 1 & 1,9 & 1,9 & 0,017 & 0,16 & 0,13 & 0,04 & 0,34 & 0,17 \\
\hline 96 & Eugenia oblongata & 1 & 1,9 & 1,9 & 0,016 & 0,16 & 0,13 & 0,04 & 0,34 & 0,17 \\
\hline 97 & Inga sp. 1 & 1 & 1,9 & 1,9 & 0,012 & 0,16 & 0,13 & 0,03 & 0,33 & 0,16 \\
\hline 98 & Endlicheria paniculata & 1 & 1,9 & 1,9 & 0,011 & 0,16 & 0,13 & 0,03 & 0,32 & 0,16 \\
\hline 99 & Rubiaceae sp. 2 & 1 & 1,9 & 1,9 & 0,011 & 0,16 & 0,13 & 0,03 & 0,32 & 0,16 \\
\hline 100 & Guarea macrophylla & 1 & 1,9 & 1,9 & 0,009 & 0,16 & 0,13 & 0,02 & 0,32 & 0,15 \\
\hline
\end{tabular}


Tabela 3 (cont.)

\begin{tabular}{llccccccccc}
\hline & Espécie & Ind & Fr.A. & Den.A & Do.A. & Fr.R. & Den.R. & Do.R. & VI & VC \\
\hline 101 & Quiina glaziovii & 1 & 1,9 & 1,9 & 0,009 & 0,16 & 0,13 & 0,02 & 0,32 & 0,15 \\
102 & Andira fraxinifolia & 1 & 1,9 & 1,9 & 0,008 & 0,16 & 0,13 & 0,02 & 0,31 & 0,15 \\
103 & Myrcia formosiana & 1 & 1,9 & 1,9 & 0,008 & 0,16 & 0,13 & 0,02 & 0,31 & 0,15 \\
104 & Eugenia aff. prasina & 1 & 1,9 & 1,9 & 0,008 & 0,16 & 0,13 & 0,02 & 0,31 & 0,15 \\
105 & Eugenia cuprea & 1 & 1,9 & 1,9 & 0,007 & 0,16 & 0,13 & 0,02 & 0,31 & 0,15 \\
106 & Miconia rigidiuscula & 1 & 1,9 & 1,9 & 0,006 & 0,16 & 0,13 & 0,02 & 0,31 & 0,15 \\
107 & Ocotea teleiandra & 1 & 1,9 & 1,9 & 0,005 & 0,16 & 0,13 & 0,01 & 0,31 & 0,14 \\
108 & Ormosia arborea & 1 & 1,9 & 1,9 & 0,004 & 0,16 & 0,13 & 0,01 & 0,30 & 0,14 \\
109 & Zollernia ilicifolia & 1 & 1,9 & 1,9 & 0,004 & 0,16 & 0,13 & 0,01 & 0,30 & 0,14 \\
110 & Guapira opposita & 1 & 1,9 & 1,9 & 0,003 & 0,16 & 0,13 & 0,01 & 0,30 & 0,14 \\
111 & Meliosma selowii & 1 & 1,9 & 1,9 & 0,003 & 0,16 & 0,13 & 0,01 & 0,30 & 0,14 \\
112 & Moraceae sp.1 & 1 & 1,9 & 1,9 & 0,002 & 0,16 & 0,13 & 0,01 & 0,30 & 0,14 \\
\hline
\end{tabular}

( $\mathrm{H}^{\prime}=4,06$ nat/indivíduo; J' = 0,86), enquanto que a floresta turfosa rasa, com 46 espécies, apresentou valores baixos para estes parâmetros $\left(\mathrm{H}^{\prime}=2,98\right.$ nat/indivíduo; J' = 0,78). A floresta turfosa profunda, com apenas 5 espécies, apresentou valores muito baixos de diversidade e equabilidade $\left(H^{\prime}=0,82\right.$ nat/indivíduo; $\left.J=0,51\right)$.

$O$ índice de Shannon da floresta sobre morrote ( $\mathrm{H}^{\prime}=4,06$ nat/indivíduo), foi bastante próximo ao de outras florestas sobre a Morraria e a Serraria Costeira da região, como em Cananéia ( $\mathrm{H}^{\prime}=3,64$ nat/indivíduo) (Melo \& Mantovani 1994), Pariquera-Açu (H' = 4,14 nat/indivíduo) (Ivanauskas 1997). A riqueza encontrada ( $\mathrm{S}=112$ ), por outro lado, foi inferior ao observado nestes estudos (157 e 183, respectivamente). Um ponto comum entre estas florestas sobre o embasamento cristalino é a ausência de uma ou poucas espécies em grande destaque na comunidade, resultando em elevada equabilidade, conforme o valor aqui encontrado $\left(J^{\prime}=0,86\right)$.

O menor número de espécies encontrado na floresta sobre morrote do PECE, em relação à estes outros estudos também sobre o embasamento cristalino, pode ser devido as suas condições de ocorrência no Parque. O morrote do PECE encontra-se naturalmente isolado de outras áreas do embasamento cristalino, sendo rodeado por turfeiras e planícies aluviais com forte influência hídrica, podendo, portanto, ser considerado como um encrave vegetacional em meio a outras formações. Desta forma, a restrição de espaço e a dificuldade de chegada de propágulos podem estar contribuindo para a diminuição da riqueza desta área.

A menor riqueza e diversidade das duas florestas turfosas do PECE em relação a floresta sobre morrote era esperada, visto que áreas encharcadas possuem reconhecidamente um menor número de espécies e menor diversidade que áreas secas (Crawford 1992,
Torres et al. 1994, Ivanauskas et al. 1997, Toniato et al. 1998).

A riqueza e diversidade observadas na floresta turfosa $\operatorname{rasa}\left(\mathrm{S}=46 ; \mathrm{H}^{\prime}=2,98\right.$ nat/indivíduo) encontram-se dentro da faixa esperada para planícies litorâneas, que é muito variável. Estes valores, no entanto, são superiores aos encontrados em outras florestas sobre turfeiras, como em Iguape/SP $(\mathrm{S}=22$; $\mathrm{H}^{\prime}=2,20$ nat/indivíduo) (Ramos Neto 1993), e no Taim/RG ( $\mathrm{S}=12 ; \mathrm{H}^{\prime}=1,89$ nat/indivíduo) (Waechter \& Jarenkow 1998). Isto parece estar relacionado ao método de amostragem, com três blocos de $1.000 \mathrm{~m}^{2}$ distribuídos ao longo da formação, que pode ter favorecido a inclusão de diferentes fácies da comunidade, além do método de inclusão de indivíduos, que pode ter favorecido a inclusão de espécies de menor porte, não amostrados em outros estudos.

O índice de diversidade obtido para a floresta turfosa profunda, com um total de cinco espécies dentre 546 indivíduos amostrados, é surpreendente na medida em que representa um dos mais baixos valores já registrados para comunidades florestais tropicais e subtropicais sem perturbação antrópica do sul e sudeste brasileiro $\left(\mathrm{H}^{\prime}=0,82\right.$ nat/indivíduo). A ausência de alterações antrópicas nesta comunidade pode ser comprovada pela observação de fotos aéreas de 1961 (escala 1:25.000), 1972 (escala 1:25.000) e 1981 (escala 1:35.000), que demonstram não ter havido mudanças de textura em sua área de ocorrência, em oposição a áreas próximas que sofreram cortes e apresentaram mudanças no padrão textural (Sztutman 2000). Mesmo a floresta sobre turfeira estudada por Waechter \& Jarenkow (1998), no Taim/RG, extremo sul do país, apresentou um maior número de espécies e maior diversidade que a floresta aqui estudada (12 espécies; 
Tabela 4. Espécies amostradas em levantamento fitossociológico da floresta turfosa rasa, no Parque Estadual da Campina do Encantado, Pariquera-Açu (SP), em ordem decrescente de VI. Ind: número de indivíduos; Fr.A.: freqüência absoluta; Den.A.: densidade absoluta; Do.A.: dominância absoluta; Fr.R.: freqüência relativa; Den.R.: densidade relativa; Do.R.: dominância relativa; VI: índice de valor de importância; VC: índice de valor de cobertura.

\begin{tabular}{|c|c|c|c|c|c|c|c|c|c|c|}
\hline & Espécie & Ind & Fr.A. & Den.A. & Do.A. & Fr.R. & Den.R. & Do.R. & VI & $\mathrm{VC}$ \\
\hline 1 & Tapirira guianensis & 127 & 93,3 & 423,3 & 8,078 & 9,49 & 24,47 & 29,16 & 63,13 & 53,63 \\
\hline 2 & Myrcia acuminatissima & 69 & 90,0 & 230,0 & 1,312 & 9,15 & 13,29 & 4,74 & 27,18 & 18,03 \\
\hline 3 & Nectandra oppositifolia & 28 & 63,3 & 93,3 & 3,548 & 6,44 & 5,39 & 12,81 & 24,64 & 18,20 \\
\hline 4 & Eugenia umbelliflora & 26 & 56,7 & 86,7 & 1,605 & 5,76 & 5,01 & 5,80 & 16,57 & 10,81 \\
\hline 5 & Alchornea triplinervia & 18 & 43,3 & 60,0 & 2,385 & 4,41 & 3,47 & 8,61 & 16,49 & 12,08 \\
\hline 6 & Rapanea venosa & 27 & 53,3 & 90,0 & 0,495 & 5,42 & 5,20 & 1,79 & 12,41 & 6,99 \\
\hline 7 & Guatteria australis & 22 & 46,7 & 73,3 & 0,651 & 4,75 & 4,24 & 2,35 & 11,34 & 6,59 \\
\hline 8 & Pouteria beaurepairei & 13 & 36,7 & 43,3 & 1,278 & 3,73 & 2,50 & 4,61 & 10,85 & 7,12 \\
\hline 9 & Psidium cattleyanum & 18 & 33,3 & 60,0 & 0,711 & 3,39 & 3,47 & 2,57 & 9,43 & 6,04 \\
\hline 10 & Gomidesia fenzliana & 14 & 30,0 & 46,7 & 0,895 & 3,05 & 2,70 & 3,23 & 8,98 & 5,93 \\
\hline 11 & Pera glabrata & 13 & 30,0 & 43,3 & 0,763 & 3,05 & 2,50 & 2,76 & 8,31 & 5,26 \\
\hline 12 & Myrcia multiflora & 8 & 26,7 & 26,7 & 0,915 & 2,71 & 1,54 & 3,30 & 7,56 & 4,84 \\
\hline 13 & Calophyllum brasiliense & 6 & 20,0 & 20,0 & 0,704 & 2,03 & 1,16 & 2,54 & 5,73 & 3,70 \\
\hline 14 & Xylopia langsdorffiana & 13 & 20,0 & 43,3 & 0,329 & 2,03 & 2,50 & 1,19 & 5,73 & 3,69 \\
\hline 15 & Styrax glabratum & 9 & 26,7 & 30,0 & 0,215 & 2,71 & 1,73 & 0,78 & 5,22 & 2,51 \\
\hline 16 & Maytenus robusta & 9 & 23,3 & 30,0 & 0,233 & 2,37 & 1,73 & 0,84 & 4,95 & 2,58 \\
\hline 17 & Byrsonima ligustrifolia & 7 & 23,3 & 23,3 & 0,283 & 2,37 & 1,35 & 1,02 & 4,74 & 2,37 \\
\hline 18 & Cybianthus peruvianus & 10 & 23,3 & 33,3 & 0,083 & 2,37 & 1,93 & 0,30 & 4,60 & 2,23 \\
\hline 19 & Matayba elaeagnoides & 5 & 13,3 & 16,7 & 0,579 & 1,36 & 0,96 & 2,09 & 4,41 & 3,05 \\
\hline 20 & Myrcia bicarinata & 7 & 20,0 & 23,3 & 0,284 & 2,03 & 1,35 & 1,03 & 4,41 & 2,37 \\
\hline 21 & Ocotea pulchella & 8 & 20,0 & 26,7 & 0,217 & 2,03 & 1,54 & 0,78 & 4,36 & 2,33 \\
\hline 22 & Persea venosa & 3 & 10,0 & 10,0 & 0,616 & 1,02 & 0,58 & 2,22 & 3,82 & 2,80 \\
\hline 23 & Ocotea aciphylla & 6 & 16,7 & 20,0 & 0,206 & 1,69 & 1,16 & 0,74 & 3,60 & 1,90 \\
\hline 24 & Euterpe edulis & 7 & 16,7 & 23,3 & 0,127 & 1,69 & 1,35 & 0,46 & 3,50 & 1,81 \\
\hline 25 & Ocotea venulosa & 6 & 16,7 & 20,0 & 0,169 & 1,69 & 1,16 & 0,61 & 3,46 & 1,77 \\
\hline 26 & Amaioua intermedia & 5 & 16,7 & 16,7 & 0,037 & 1,69 & 0,96 & 0,13 & 2,79 & 1,10 \\
\hline 27 & Endlicheria paniculata & 4 & 13,3 & 13,3 & 0,031 & 1,36 & 0,77 & 0,11 & 2,24 & 0,88 \\
\hline 28 & Eugenia stigmatosa & 3 & 10,0 & 10,0 & 0,168 & 1,02 & 0,58 & 0,61 & 2,20 & 1,19 \\
\hline 29 & Andira fraxinifolia & 3 & 10,0 & 10,0 & 0,067 & 1,02 & 0,58 & 0,24 & 1,84 & 0,82 \\
\hline 30 & Rapanea ferruginea & 3 & 10,0 & 10,0 & 0,025 & 1,02 & 0,58 & 0,09 & 1,68 & 0,67 \\
\hline 31 & Symplocos variabilis & 3 & 6,7 & 10,0 & 0,025 & 0,68 & 0,58 & 0,09 & 1,35 & 0,67 \\
\hline 32 & Marlierea obscura & 2 & 6,7 & 6,7 & 0,053 & 0,68 & 0,39 & 0,19 & 1,25 & 0,58 \\
\hline 33 & Maprounea guianensis & 2 & 6,7 & 6,7 & 0,039 & 0,68 & 0,39 & 0,14 & 1,20 & 0,53 \\
\hline 34 & Aniba firmula & 2 & 6,7 & 6,7 & 0,016 & 0,68 & 0,39 & 0,06 & 1,12 & 0,44 \\
\hline 35 & Sloanea monosperma & 1 & 3,3 & 3,3 & 0,162 & 0,34 & 0,19 & 0,58 & 1,12 & 0,78 \\
\hline 36 & Geonoma schottiana & 2 & 6,7 & 6,7 & 0,012 & 0,68 & 0,39 & 0,04 & 1,11 & 0,43 \\
\hline 37 & Podocarpus sellowii & 1 & 3,3 & 3,3 & 0,149 & 0,34 & 0,19 & 0,54 & 1,07 & 0,73 \\
\hline 38 & Ilex pseudobuxus & 1 & 3,3 & 3,3 & 0,099 & 0,34 & 0,19 & 0,36 & 0,89 & 0,55 \\
\hline 39 & Ternstroemia brasiliensis & 1 & 3,3 & 3,3 & 0,029 & 0,34 & 0,19 & 0,10 & 0,64 & 0,30 \\
\hline 40 & Didymopanax calvum & 1 & 3,3 & 3,3 & 0,026 & 0,34 & 0,19 & 0,09 & 0,62 & 0,28 \\
\hline 41 & Trichipteris atrovirens & 1 & 3,3 & 3,3 & 0,022 & 0,34 & 0,19 & 0,08 & 0,61 & 0,27 \\
\hline 42 & Ilex theezans & 1 & 3,3 & 3,3 & 0,019 & 0,34 & 0,19 & 0,07 & 0,60 & 0,26 \\
\hline 43 & Blepharocalyx salicifolius & 1 & 3,3 & 3,3 & 0,012 & 0,34 & 0,19 & 0,04 & 0,58 & 0,24 \\
\hline 44 & Clusia criuva & 1 & 3,3 & 3,3 & 0,012 & 0,34 & 0,19 & 0,04 & 0,57 & 0,23 \\
\hline 45 & Guapira opposita & 1 & 3,3 & 3,3 & 0,007 & 0,34 & 0,19 & 0,03 & 0,56 & 0,22 \\
\hline 46 & Weinmannia cf. paulliniifolia & 1 & 3,3 & 3,3 & 0,007 & 0,34 & 0,19 & 0,02 & 0,56 & 0,22 \\
\hline
\end{tabular}


Tabela 5. Espécies amostradas em levantamento fitossociológico da floresta turfosa profunda, no Parque Estadual da Campina do Encantado, Pariquera-Açu (SP), em ordem decrescente de VI. Ind: número de indivíduos; Fr.A.: freqüência absoluta; Den.A.: densidade absoluta; Do.A.: dominância absoluta; Fr.R.: freqüência relativa; Den.R.: densidade relativa; Do.R.: dominância relativa; VI: índice de valor de importância; VC: índice de valor de cobertura.

\begin{tabular}{|c|c|c|c|c|c|c|c|c|c|c|}
\hline & Espécie & Ind & Fr.A. & Den.A. & Do.A. & Fr.R. & Den.R. & Do.R. & VI & $\mathrm{VC}$ \\
\hline 1 & Ternstroemia brasiliensis & 229 & 100 & 1145 & 10,84 & 40 & 41,94 & 56,50 & 138,44 & 98,44 \\
\hline 2 & Ilex pseudobuxus & 302 & 100 & 1510 & 8,19 & 40 & 55,31 & 42,68 & 137,99 & 97,99 \\
\hline 3 & Clusia criuva & 7 & 25 & 35 & 0,06 & 10 & 1,28 & 0,31 & 11,59 & 1,59 \\
\hline 4 & Ilex dumosa & 6 & 20 & 30 & 0,08 & 8 & 1,10 & 0,40 & 9,50 & 1,50 \\
\hline 5 & Ocotea pulchella & 2 & 5 & 10 & 0,02 & 2 & 0,37 & 0,12 & 2,48 & 0,48 \\
\hline
\end{tabular}

$\mathrm{H}^{\prime}=1,89$ nat/indivíduo), através da amostragem de 120 indivíduos. Para este autor, estas características encontradas no Taim são em função do alagamento permanente do solo, associado à latitude austral da região.

Na floresta sobre turfeira espessa do PECE ocorreu também o mais baixo valor de equabilidade $(\mathrm{J}=0,51)$ dos estudos de comunidades florestais tropicais e subtropicais sem perturbação antrópica do sul e sudeste brasileiro. Este baixo valor reflete a dominância de Ternstroemia brasiliensis e Ilex pseudobuxus que juntas totalizaram $97 \%$ dos indivíduos amostrados, dando um caráter bastante homogêneo para esta unidade florestal.

A determinação deste padrão vegetacional pouco complexo e extremamente diferenciado de outras comunidades tropicais e subtropicais, não está relacionado unicamente ao encharcamento permanente do solo. Isto porque a floresta turfosa rasa do PECE

Tabela 6. Parâmetros estruturais calculados para levantamentos fitossociológicos do estrato arbóreo de florestas do Parque Estadual da Campina do Encantado, Pariquera-Açu (SP): FSM. floresta sobre morrote; FTR: floresta turfosa rasa; FTP. floresta turfosa profunda.

\begin{tabular}{lccc}
\hline Parâmetros & FSM & FTR & FTP \\
\hline n. de indivíduos amostrados & 768 & 519 & 546 \\
n. de famílias & 38 & 24 & 4 \\
n. de espécies & 112 & 46 & 5 \\
n. de espécies exclusivas & 97 & 27 & 1 \\
n. de espécies que compõem & 15 & 6 & 2 \\
50\% do VI & & & \\
Altura média do dossel (m) & 25 & 15 & 5 \\
D (indivíduos.ha' ${ }^{-1}$ ) & 1422 & 1730 & 2730 \\
AB (m ${ }^{2}$. ha & \\
H' (diversidade de Shannon) & 39,3 & 27,7 & 19,2 \\
J (equabilidade) & 0,06 & 2,98 & 0,82 \\
& & 0,78 & 0,51 \\
\hline
\end{tabular}

também é permanentemente encharcada, chegando até mesmo a apresentar uma lâmina d'água sobre o substrato durante certos períodos do ano e, no entanto, apresenta maior complexidade estrutural do que a floresta turfosa profunda, que nunca apresenta a água sobre o substrato. Deste modo, a diferenciação de distintos tipos florestais sobre substratos encharcados envolve não somente a intensidade e período das inundações, mas também outros fatores como o tempo de permanência da água no sistema e suas características químicas.

A água intersticial, em comunidades sobre substrato turfoso, é apontada como a principal fonte de nutrientes para as plantas (Heinselman 1975; Damman 1986; Vitt \& Chee 1990). Diferentes unidades vegetacionais em áreas turfosas são frequientemente relacionadas à distintas composições químicas da água intersticial. (Johnson 1977; Vitt \& Chee 1990; Glaser 1992; Anderson et al. 1995). Análises químicas da água intersticial nas duas florestas turfosas do PECE demonstraram haver diferenças marcantes em suas composições nutricionais, provavelmente relacionadas a processos de oxi-redução de diferentes intensidades (Sztutman 2000). Existe a possibilidade da floresta turfosa profunda estar sujeita a resíduos metabólicos tóxicos ao desenvolvimento vegetacional, produzidos pela atividade microbiana anaeróbia (Sztutman 2000).

É interessante notar que, na área relativamente pequena do PECE (cerca de 3.000 ha), ocorrem tipos florestais contíguos e muito distintos entre si, do ponto de vista fisionômico, florístico e estrutural. Salienta-se que as três unidades vegetacionais estudadas estão distantes entre si não mais do que $1.500 \mathrm{~m}$ em linha reta. Considerando que não ocorrem acidentes topográficos na área, estão sujeitas rigorosamente ao mesmo clima. Esta grande heterogeneidade sobre as planícies litorâneas, mesmo entre áreas contíguas e 
muito próximas entre si, indica a necessidade de esforços conservacionistas serem direcionados para o mosaico ambiental, considerando o maior número de situações ambientais possíveis, afim de se exercer a efetiva conservação da biodiversidade in situ. Essa importância é ainda realçada quando verifica-se a existência de ambientes ainda muito pouco conhecidos, como é o caso da floresta turfosa profunda do PECE, que apresentou características muito distintas de outras comunidades já estudadas nas regiões sul e sudeste brasileiras.

Agradecimentos - Os autores agradecem ao CNPq pela concessão de bolsa de mestrado ao primeiro autor, e à FAPESP, pela concessão de auxílio pesquisa para o desenvolvimento deste trabalho. Agradecem também ao Prof. Dr. Sergius Gandolfi pelas contribuições oferecidas, a Rogério Lupo pela elaboração dos perfis, a equipe do Parque Estadual da Campina do Encantado pelo apoio logístico e aos seguintes taxonomistas, pelas identificações realizadas: C. Carneiro (Pouteria), J.B. Baitello (Lauraceae), M.L. Kawasaki (Myrtaceae), L. Rossi (Humiriaceae e Elaeocarpaceae), M. Groppo (Aquifoliaceae), S. Jung-Mendaçolli (Rubiaceae, Araliaceae e Myrsinaceae), R.M. Carvalho-Okano (Celastraceae), R. Mello-Silva (Annonaceae), R. Goldenberg (Melastomataceae).

\section{Referências bibliográficas}

ANDERSON, D.S., DAVIS, R.B. \& JANSSENS, J.A. 1995. Relationships of bryophytes and lichens to environmental gradients in Maine peatlands. Vegetatio 120:147-159.

ARAUJO, D.S.D. 1987. Restingas: síntese do conhecimento para a costa sul-sudeste brasileira. In Simpósio sobre Ecossistemas da Costa Sul-Sudeste Brasileira (S. Watanabe, coord.). ACIESP, Cananéia, v.1, p.333-347.

CONSÓRCIO MATA ATLÂNTICA. 1992. Reserva da Biosfera da Mata Atlântica. Plano de Ação. Universidade Estadual de Campinas, Campinas.

COLWELL, R.R. 1997. EstimateS: Statistical estimation of species richness and shared species from samples. Version 5.0. Guia do usuário e programa disponíveis no: http:// viceroy.eeb.uconn.edu/estimates

CRAWFORD, R.M.M. 1992. Oxygen avaliability as an ecological limit to plant distribution. Advances in Ecological Research 23:93-185.

DAMMAN, A.W.H. 1986. Hydrology, development and biogeochemistry of ombrogenous peat bogs with special reference to nutrient relocation in a western Newfoundland bog. Canadian Journal of Botany 64:384-394.

EITEN, G. 1970. A vegetação do estado de São Paulo. Boletim do Instituto de Botânica 7:1-22.
GLASER, P.H. 1992. Raised bogs in eastern North America regional controls for species richness and floristic assemblages. Journal of Ecology 80:535-554.

HEINSELMAN, M.L. 1975. Boreal peatlands in relation to environment. In Coupling of land and water systems (A.D. Hasler, ed.). Spring-Verlag, New York, p.93-103.

IPT. 1981. Prospeção regional de turfa no estado de São Paulo. São Paulo. (Relatório IPT 15.318).

IVANAUSKAS, N.M. 1997. Caracterização florística e fisionômica da floresta atlântica sobre a formação Pariquera-Açu, na zona da morraria costeira do estado de São Paulo. Dissertação de mestrado, Universidade Estadual de Campinas, Campinas.

IVANAUSKAS, N.M., RODRIGUES, R.R. \& NAVE, A.G. 1997. Aspectos ecológicos de um trecho de floresta de brejo em Itatinga, SP: florística, fitossociologia e seletividade de espécies. Revista Brasileira de Botânica 20:139-153.

JOHNSON, E.A. 1977. A multivariate analysis of the niches of plant populations in raised bogs. I. Niche dimensions. Canadian Journal of Botany 55:1201-1210.

JOLY, A.B., LEITÃO FILHO, H.F. \& SILVA, S.M. 1991. O patrimônio florístico. In Mata Atlântica (I.G. Câmara, ed.). Editora Index Ltda e Fundação Mata Atlântica, São Paulo, p.97-107.

LEITÃO FILHO, H.F. 1982. Aspectos taxônomicos das florestas do estado de São Paulo. Silvicultura em São Paulo 16A:197-206.

LEITÃO FILHO, H.F. 1994. Diversity of arboreal species in atlantic rain forest. Anais da Academia Brasileira de Ciências 66:91-96.

LEPSCH, I.F., SAKAI, E., PRADO, H., \& RIZZO, L.T.B. 1998. Levantamento de reconhecimento com detalhes dos solos da região do rio Ribeira de Iguape no estado de São Paulo (mapa). Informe preliminar do Instituto Agronômico de Campinas, Campinas.

MANTOVANI, W. 1992. A vegetação sobre a restinga de Caraguatatuba, SP. Revista do Instituto Florestal 4:139-144.

MANTOVANI, W. 1998. Dinâmica da Floresta Pluvial Atlântica. In Anais do IV Simpósio de Ecossistemas Brasileiros (S. Watanabe, coord.). ACIESP, São Paulo, v.2, p.1-20.

MELO, M.M.R.F. \& MANTOVANI, W. 1994. Composição florística e estrutura de trecho de mata atlântica de encosta, na Ilha do Cardoso (Cananéia, SP, Brasil). Boletim do Instituto de Botânica 9:107-158.

MUELLER-DOMBOIS, D. \& ELLENBERG, M. 1974. Aims and methods in vegetation ecology. John Wiley \& Sons, New York.

PIELOU, E.C. 1975. Ecological diversity. John Wiley \& Sons, New York.

RAMOS NETO, M.B. 1993. Análise florística e estrutural de duas florestas sobre a restinga de Iguape, São Paulo. Dissertação de mestrado, Universidade de São Paulo, São Paulo. 
RODRIGUES, R.R. 1988. Métodos fitossociológicos mais usados. Casa da Agricultura. 10:20-24.

SÃO PAULO. 1998. Planos de Manejo de Unidades de Conservação. Parque Estadual do Pariquera Abaixo Plano de Gestão Ambiental - fase 1. Secretaria do Meio Ambiente, São Paulo, 87p.

SHEPHERD, G.J. 1995. Programa FITOPAC 1. Manual do usuário. Universidade Estadual de Campinas, Campinas

SUGIYAMA, M. 1998. Estudo de florestas da restinga da Ilha do Cardoso, Cananéia, São Paulo, Brasil. Boletim do Instituto de Botânica 11:119-159.

SZTUTMAN, M. 2000. O mosaico vegetacional da Planície Litorânea de Cananéia/Iguape e suas relações com o ambiente: um estudo de caso no Parque Estadual da Campina do Encantado, Pariquera-Açu (SP). Dissertação de mestrado, Escola Superior de Agricultura "Luiz de Queiroz", Universidade de São Paulo, Piracicaba.

TABARELI, M. \& MANTOVANI, W. 1999. Riqueza de espécies arbóreas na floresta atlântica de encosta no estado de São Paulo (Brasil). Revista Brasileira de Botânica 22:217-223.
TONIATO, M.T.Z., LEITÃO FILHO, H.F. \& RODRIGUES, R.R. 1998. Fitossociologia de um remanescente de floresta higrófila (mata de brejo) em Campinas, SP. Revista Brasileira de Botânica 21:197-210.

TORRES, R.B., MATTHES, L.A.F. \& RODRIGUES, R.R. 1994. Florística e estrutura do componente arbóreo de mata de brejo em Campinas, SP. Revista Brasileira de Botânica 17:189-194.

VITT, D.H. \& CHEE, W.L. 1990. The relationship of vegetation to surface water chemistry and peat chemistry in fens of Alberta, Canada. Vegetatio 89:87-106.

WAECHTER, J.L. 1985. Aspectos ecológicos da vegetação de restinga no Rio Grande do Sul, Brasil. Comunicações do Museu de Ciências Série Botânica 33:49-68.

WAECHTER, J.L. 1990. Comunidades vegetais das restingas do Rio Grande do Sul. In II Simpósio de Ecossistemas Brasileiros (S. Watanabe, coord.). ACIESP, São Paulo, v. 3, p.228-248.

WAECHTER, J.L. \& JARENKOW, J.A. 1998. Composição e estrutura do componente arbóreo nas matas turfosas do Taim, Rio Grande do Sul. Biotemas 11:49-69. 